\title{
Strategic Marketing Issues for an Emerging Market Firm to go Global
}

\author{
Nagasimha Balakrishna Kanagal ${ }^{1}$ \\ ${ }^{1}$ Indian Institute of Management, Bangalore, India \\ Correspondence: Nagasimha Balakrishna Kanagal, Indian Institute of Management, Bannerghatta Road, \\ Bangalore, 560076, India.
}

\author{
Received: April 5, 2017 \\ doi:10.5539/ibr.v10n6p35 \\ Accepted: May 2, $2017 \quad$ Online Published: May 4, 2017 \\ URL: https://doi.org/10.5539/ibr.v10n6p35
}

\begin{abstract}
Emerging markets, as of recent times, are going through phases of liberalization towards market economies, increasing privatization, and are witnessing an emphasis of emerging markets' governments towards globalization. There has been a rise in the contribution of emerging market firms to the economies of emerging markets. A study with a purpose to conceptualize strategic marketing issues for an emerging market firm to go global is significant, given that success in overseas marketing ventures is critical to sustain the phases of globalization. The challenge is to enter, obtain market share, and sustain in advanced economies and other emerging markets. This paper attempts to address the conceptualization and the challenge. The method of the study is to (i) define strategic marketing, outline and distinguish the different types of firms marketing overseas international, multinational, and transnational / global; and (ii) analyze using extant literature, the aspects and issues of global entry and implementation of global marketing strategy. The study, post analysis, conceptualizes and postulates three moderating success factors, wherein consideration of these factors will aid the emerging market firm in improving its performance (i) acculturation processes in global businesses; (ii) achievement of global marketing synergies; and (iii) the importance of overcoming global negatives. Given that conditions for global entry and implementing global marketing strategy are met, and the three success moderating factors are addressed, the study recognizes that it is necessary to address the competitive forces in the global environment to be able to obtain an optimal share of the market. The study includes a discussion based on an in-depth interview with a leading garment exporter in Bangalore, India, to understand global entry and global marketing strategy implementation. In conclusion, it can be stated that that (i) an explicit process to address global negatives is required to overcome the perceptual gap of emerging market firms on deliverables; (ii) explicit attention to the achievement of global market synergies has to be given by global marketing strategists.
\end{abstract}

Keywords: transnational / global firms, global positives, global negatives, acculturation process, market acceptance barriers, global market synergies

\section{Introduction}

Emerging markets, as of recent times, are going through phases of liberalization towards market economies, increasing privatization, and are witnessing an emphasis of emerging markets' governments towards globalization. There has been a rise in the contribution of emerging market firms to the economies of emerging markets. As of the present, companies from emerging markets account for (Cuervo-Cazurra et. al, 2016) about 25 percent of the Fortune Global 500, up from 2 percent in 1995. Further multi-nationalization of emerging market (BRIC countries) firms is taking place with 24 firms from Brazil, 27 firms from Russia, 56 firms from India, and 180 firms from China, among the Forbes Global 2000 list of the largest publicly traded firms in 2015. A study with a purpose to conceptualize strategic marketing issues for an emerging market firm to go global is significant, given that success in overseas marketing ventures is critical to sustain the phases of globalization. The challenge is to enter, obtain market share, and sustain in advanced economies and other emerging markets. This paper attempts to address the conceptualization and the challenge.

In a very simple sense, strategic marketing pertains to important decision making in marketing. Marketing, as a concept, is the conceptualization, design, build-up, execution and monitoring of marketing programs to satisfy consumer needs and wants, while at the same time adhering to organizational objectives. The strategic emphasis to marketing refers to (for the purpose of this paper) (a) long term implications of the marketing decisions taken; and / or (b) huge investments made in the context of the marketing decisions. Given that markets are uncertain, contingency build-ups are an integral part of strategic marketing decision making. 
The objective of strategic marketing or marketing strategy is to improve long term financial performance of the firm. However in the context of strategic marketing in the global context for emerging market firms, the objective could also be to obtain a long run market share overseas. Marketing of products overseas has other important implications such as improvement of product quality, adaptation to global needs and wants, and consequent trickle down of improved marketing practices in the domestic market. The context in a global situation could be very different from that existing within the domestic economy, and marketing strategy may have to be reformulated if not laid out afresh. Adaptation to country specific government attitudes and policies will be required. Resource allocation and investment decisions are complex. The value of foreign currency, especially the dollar, makes global expenditures large in emerging market terms, making tactical decisions, as well as strategic decisions, important and worthy of top management attention. All these factors suggest that a marketing strategy formulation for a firm going global is very important and needs separate study and attention.

\section{Method}

The study outlines the importance of strategic marketing issues for emerging market firms going global. The method of the study is to (i) define strategic marketing, outline and distinguish the different types of firms marketing overseas - international, multinational, and transnational / global; and (ii) analyze using extant literature, the aspects and issues of global entry and implementation of global marketing strategy. The study post analysis, conceptualizes and postulates three moderating success factors wherein consideration of these factors will aid the emerging market firm in improving its performance. The study includes a discussion based on an in-depth interview with a leading garment exporter in Bangalore, India, to understand global entry and global marketing strategy implementation. Conclusions of the topic of the study follow thereafter.

\section{Analysis}

\subsection{Cross-Border Arrangements in Firms with Overseas Operations}

\subsubsection{International Firm}

A domestic parent establishes a separate division or organization in the home country itself to deal with marketing in one or more host countries. Sales / marketing offices may be established overseas. The concept of home country and host country division is distinct. In international firms there is a movement across borders, of mostly goods through sales/ marketing offices or overseas distributors, and with support services through service offices or provided by the overseas distributor.

\subsubsection{Multinational Firm}

A multinational firm popularly known as an MNC, operating in the home country and called parent, establishes separate organizations in each host country, along with investments to produce and market in each of the host countries. The concept of home country and host country continues to exist with the division close to being distinct. MNCs are also multi-domestic in their character with adaptations of the market offering in strategy and culture being most evident. MNCs suggest extensive international operations. Multinational firms are seen to work with cross-border movement of (i) goods and support service; and (ii) financial capital.

\subsubsection{Transnational Firm / Global Firm}

It is a multinational firm with extensive international operations throughout the world, and exhibits cross border movement of (i) goods and support services; (ii) capital or money or investments; and (iii) people. The emergence of a transnational firm is closely linked with the emergence of an international service economy, supported by the movement of large intellectual capital to and from various host countries, and among countries. The concept of the global firm includes attempts to coordinate and integrate operations across borders to achieve potential synergies. There are efforts to rationalize investments in various countries and achieve optimal resource allocation. The divisions between home country and host country is minimal, as the management views the world market as a series of interrelated and interlinked markets. A cohesive organization culture tends to develop in the transnational / global firm, even though consumers' enculturated individuality, and the country's organizational culture impacted by ethnic cultures are deep rooted and tend to remain. The arrival of global firms could possibly signal the arrival of global consumers.

\subsection{Global or Overseas Entry}

The major decisions involved in going international (Kotler \& Keller, 2016) include (i) deciding whether to go abroad; (ii) deciding which markets to enter; and (iii) deciding how to enter those markets.

First, in deciding whether to go abroad, the goals and objectives of the firm must permit the firm to do so. Attractive market opportunities must be present that can be successfully serviced by the domestic firm. If 
necessary, firms should be willing to redefine the business definition to adapt to international markets. This includes customer benefits, customer segments, technology employed, and participation in various stages of the value chain. In addition there must be a strong motivation to go abroad, which could be higher profit opportunities abroad, huge markets abroad of which even a small share might suffice, or domestic customers going global who need to be serviced. Global motivations could also include (Aaker \& McLoughlin, 2010) obtaining scale economies, global brand associations, global innovation, access to low cost labor or raw materials, access to national investment incentives or government incentives, cross subsidization, dodging trade barriers, and access to strategically important markets. The firm is best placed if it can leverage its core competencies in international markets. In taking the decision to go abroad, hurdles have to be overcome such as foreign go vernment regulations, differences in culture, and lack of foreign experience. Further, the home country firm should be clear about the resources it is willing to commit to go global, whether these resources are adequate, and for how long it is ready to invest resources in the host markets.

Second, in deciding which markets to enter, the following factors are typically considered (a) market attractiveness as determined by the total market potential and the realizable demand for this particular firm; (b) whether the foreign country risk is identifiable and manageable; (c) whether the key success factors of that particular country can be successfully met by the inherent or developable strengths of this particular firm; in other words does the firm enjoy some key competitive advantages in relation to competition? (d) whether supplier sources can be identified, and if yes, are they attractive? and (e) favorability of the overall macro environment of the host country.

In deciding to enter a particular market, it is necessary to examine and understand the trading block to which the country belongs, and whether the firm's home country has reasonable trade flows with the host country's trading block. The prominent trading blocks are NAFTA, and European Community. Competition within the European trading block is intensifying as the member countries attempt to provide pan European products.

The pattern of entry into different countries is also to be noted. In general the pattern is decided by how the order book goes. However, it is not advisable to enter countries too fast, as the home firm may not be able to cope with the sudden growth of activities. It is best to enter those countries where deeper commitments can be made and where there is the possibility of deeper penetration.

Third, in deciding how to enter the market, there are typically five routes (a) indirect export, (b) direct export, (c) licensing, (d) joint ventures / alliances, and (e) direct investment.

When the company goes by the order book, indirect export is a preferred option. It is possible to have independent intermediaries and export through them. When the firm tries to make a concerted and planned effort to market in one or more countries, then direct export is preferred. An international sales office may be set up for this purpose. When the market is significant and when the home country firm can retain control over the value addition, then the licensing route can be chosen. Joint ventures / alliances can be forged mainly as a project specific measure to be able to imbibe host country procedures and culture. In the long run joint ventures will succeed when both the partners bring to the table a fair measure of value inputs that are not reasonably exchangeable; for example, a high technology firm such as GE brings in technological innovation and a firm such as WIPRO brings in developmental effort. Direct investment is warranted when there is a reasonable assurance of a sustained market that promises more than a fair share of returns. Choice of actual direct investments is based on experience, judgment, insight, foresight and analysis.

In the Indian context, though firms are fairly familiar with indirect export and direct export, a method to supplement direct export with investments in marketing, sales and servicing could be the route to take. This can be extended by participation in global assembly facilities and global outsourcing with time to come. The software industry is in this extended phase by being part of the global value chain.

The choice of the entry mode, being strategic, needs contingency planning, and given the limited information of foreign host markets, needs to be experimental or option based that has adequate flexibility in action setting (Buckley, 2014).

\subsection{Global Logic}

Global logic is a rationale for globalization or to go global. We can look for global logic in a number of areas that include the following (a) global customer logic; (b) global purchasing logic; (c) global information logic; (d) global competitive logic; (e) global industry logic; (f) global size logic; and (g) global regulatory logic (Jeannet, 1999).

\subsubsection{Global Customer Logic}

For a firm to go global, it is not enough if the overseas customers have similar need sets. It is necessary that the features and benefits demanded in the host markets are similar to the features and benefits provided in the home 
market. In other words, it should be possible for the domestic firm to match up with global products on both features and benefits. In the cellular market, handsets marketed across the world have their features and benefits matched up with the requirement of the local markets.

\subsubsection{Global Purchasing Logic}

Does the overseas buyer use global sourcing methods? If yes, is the buyer firm open to products supplied from the considered firm's home country or is the buyer firm restricting itself to countries within the trading block or developed countries? Is the overseas buyer demanding supplies from the considered firm on a global basis, and hence behaving as a global customer? Does the exporting firm have core strengths to supply to a global customer? Can the exporting firm be a part of the value chain of the overseas or global buyer; for example, as in the automotive component industry? Have other home country firms, which have operations overseas, demanded supplies from the considered exporting firm?

\subsubsection{Global Information Logic}

Is it possible to get the home country firm's products and services listed in international magazines and trade catalogs where purchasers are most likely to look? Is it possible to get international certifications for quality, customer satisfaction, and for successful installation and usage in overseas markets? Can such certifications be advertised to home country firm's advantage? It should also be possible to advertise and provide information through the World Wide Web. Can the home country firm get superior reviews in trade shows and seminars? In short, wherever information is being traded before, during or after purchase, can the home country firm participate in the global circuit of information? If the answer is yes to these questions, then the exporting firm has global information logic.

\subsubsection{Global Competitive Logic}

The first step is to understand the competitive setting that exists for the particular industry or product market in which the firm is going to compete overseas. It is necessary to check if the market overseas is dominated on a country by country basis with national players, resulting in a situation that the considered exporting firm encounters different players in different countries. It is also necessary to examine if the overseas market has a regional or trading block competitive setting. It could also be possible that the competitive logic is global as in the carbonated soft drink markets with Coca-Cola and Pepsi being the global players. The second step, given the competitive setting, is to check whether the firm can adapt itself to the competitive setting. The considered firm has to get 'favorable intentions to buy' from customers in a given competitive setting. In short, the exporting firm has to be a visible competitor, to obtain global competitive logic.

\subsubsection{Global Industry Logic}

When the key success factors (KSFs) of an industry are the same worldwide, then global industry logic is said to exist. Further the logic is strengthened when resources can be shared worldwide. One example is the software industry. Another would be the paint industry.

\subsubsection{Global Size Logic}

Certain firms such as those in the pharmaceutical industry operate on high R\&D budgets with large lead times that they need a critical mass to succeed. So they enter as many markets as possible. Domestic firms needing such size, should actively confirm that other dimensions of market acceptance of such products are favorable. Market acceptance is discussed in the sections to follow.

\subsubsection{Global Regulatory Logic}

The global regulatory environment is improving considerably with the economy in many newly industrializing markets moving towards - LPG - liberalization, privatization and globalization. There is a strong case for similar regulatory environments across countries when the technological standards are all global or are moving towards one common standard. When regulations differ across countries, it is necessary to adapt products as required, so as to serve those markets. However due to the forces of globalization, customers are ultimately served by firms that are a part of a network of a connected global value chain. The issue is how the firm should be a part of this network and provide value so that a sustainable place in world markets could be obtained.

\subsubsection{Global Logic Index}

It is possible to give an index rating to each of the seven logic elements and then give a weighting to each of the logic elements as decided by the type of product market, firm resources and capabilities, and the global market forces that includes the competitive forces and the global context. A weighted index for global logic could then be derived which indicates the intensity with which the efforts of the firm to take its products overseas is supported. 


\subsection{Implementing Global Marketing Strategy}

Once global motivations and global logic have been worked out successfully and the firm has laid out its process of entering global or overseas markets, then various aspects of implementing the global marketing strategy have to be considered, as outlined below (Douglas \& Craig, 1995).

\subsubsection{Globalization vs. Adaptation Strategies}

Global standardization vs. adaptation is a central theme of the marketing program. A global approach will guide a homogenous market across countries and standardization will pervade. A multinational approach on the other hand will regard the global market as an inter-linkage of nation markets that have to be separately catered to. A glocal approach standardizes the core elements and localizes other elements. For an emerging market firm to go global, it is advisable to toe the line of adaptation, as developed markets are mature and are at an advanced stage of need-want gratification. However there may be certain product markets where standardization across countries will prevail.

In considering adaptation, the simplest adaptation to consider is that of communication to suit the needs of overseas markets. Certain markets may demand a certain degree of forward invention in product or service wherein advanced procedures or methods are to be used in the development or production of goods and services. This usage of forward invention has to be communicated to the overseas buyer to signal quality. With regard to price, it is best to follow the market-based dictates as to what price is optimal in a particular country. Distribution is a critical area where assistance of overseas sellers may have to be enlisted to complete the selling cycle.

\subsubsection{Deciding on the Marketing Organization}

Depending on the stage of internationalization of the firm, an appropriate marketing organization can be evolved. An export department is the most basic with independent overseas distributors. An international division with overseas sales organizations could be next. A global organization with investments and facilities in multiple countries that are all inter linked could be targeted in instances when the assured market is reasonable and sustainable. Challenges in the marketing organization of emerging market multinationals include (i) evolution of governance mechanisms for emerging market multinational firms that need to be dealt with in cooperation and subtlety; (ii) managing their overseas subsidiaries; (ii) transferring knowledge from the overseas subsidiary; and (iii) knowledge management of the emerging market firm, when the overseas subsidiary happens to be from advanced economies (Meyer and Peng, 2016). Tightly coupled with these aspects of deciding on marketing organization, is the need to recognize the importance of filling institutional voids in the market society and institutional environments of host markets, when host markets are themselves other emerging markets.

\subsubsection{Phases of International Marketing Development}

In entering a particular country market it is useful to check the stage of international marketing development of the main competitors in the product market or industry. In general there are three phases (a) Initial foreign market entry; (b) Local or national market expansion; (c) Global rationalization.

If the product category in the overseas market is in the initial stage of evolution, then it is convenient for home country firms to enter overseas markets and to modify consumer preferences and create an image. The strategic thrust would be a 'geographic market extension' of the firm's domestic position. However if the overseas market is mature and the firm concerned is in the stage of initial overseas market entry, then the challenges and barriers in the overseas market depending on the maturity of the industry there has to be assessed.

If the product category in the overseas market is in the next stage of local market expansion that could possibly mean home country firms have to obtain a beachhead in the overseas market. A beachhead signals that a firm has to obtain a foothold in the overseas market; the foothold or beachhead accrues to the firm when it has obtained significant market share in the product category in the overseas market, and has the sustainable competitive advantages to support and further the significant presence it has obtained, This implies that the home country firm entering directly will have to work that much harder to make an impression on the foreign customer. It could also mean that the home country firm has to provide or demonstrate considerable value addition over competitors. It may become necessary to tailor marketing strategy programs country by country. Further, the home country firm may have to acquire overseas, some local products / brands to create an immediate beachhead and subsequently leverage competencies in brand name, technical expertise, and corporate reputation. To maintain efficiency, the home country firm might have to market to several closer countries, and share advertisement, promotional and distribution costs. The strategic thrust would be to obtain an immediate beachhead.

If the competing firms are in a stage of global rationalization, then the home country firm is well advised to attempt to be part of the global value chain of the customer without getting into a head-on confrontation with 
globally rationalized competitors. Global rationalization indicates the coordination and integration of decision systems and operations across nation borders and optimal allocation of resources worldwide.

It has been researched (Cuervo-Cazurra and Ramamurti, 2014) that the gradual construction of international value chains in highly competitive and dynamic international markets with a transition from domestic to international management phase, is still a major challenge for Brazilian multinational enterprises.

\subsubsection{Partial Global Strategies}

A true global operator is one whose asset distribution strategies and market coverage strategies are both global. Companies such as General Motors emphasize asset globalization, whereas firms such as Swatch try to operate from the home base as much as possible and emphasize market global strategies. When globalization is implemented, typically the globalization paradigm is applied to one or a few dimensions of marketing strategy. It is rarely, if ever, applied to all dimensions of marketing strategy. Accordingly we have different categories of partial global strategies such as (a) global branding strategy; (b) global advertising strategy; (c) global product strategy; (d) global account strategy; (e) global R\&D strategy; and (f) global segment strategy.

It is for the home country firm to understand the dimension on which it can globalize successfully, whether it is in particular segment, or whether it is in servicing a global customer worldwide; that means the firm has to select, one or more among the partial global strategies mentioned above in (a) to (f). This identification of its core strength of globalization will improve its ability to implement marketing strategy.

\subsubsection{Developing a Global Mindset}

To successfully implement global marketing strategy, a corporate global mindset is useful. The evolution of a corporate global mindset involves the following (a) global teams and task forces; (b) global functions such as global marketing and global finance; (c) global organization; (d) global responsibilities; (e) global market understanding; (f) formal global strategy; (g) global mandates / objectives; (h) global information technology; and (i) global competition under consideration.

\section{Findings / Postulates and Results: Moderators of Success in Global Marketing Strategies}

In recent times, several countries especially the emerging markets have undergone a phase of deregulation with accompanying liberalization or market reforms, to align domestic firms to market based economies. In addition, the governments of emerging markets such as India have placed emphasis on building the export economy with appropriate globalization incentives also called export incentives. In this scenario it is important for firms going global or for firms of developed markets who are already in multiple countries, to examine more closely the moderating factors that contribute to success of their global marketing strategies. Aspects of such factors are outlined below.

\subsection{Importance of Acculturation Processes in a Global Business}

\subsubsection{Market Aspect of a Global Business}

Consumers in host markets have strongly grounded enculturated individualities in their home markets, and marketers addressing overseas markets should put in place programs and processes for communication to and acculturation of host market consumers so that they can appreciate the home country's culture and achieve superior need-use gratification. When marketing to advanced countries, these host country consumers are in an advanced stage of need-want gratification and need-use gratification, and thus it is more difficult to provide value beating propositions to them; under such conditions acculturation helps in supporting home country marketers in host markets. Further when selling to foreign organizations in business to business (B2B) markets, trickle down of best practices occurs better if acculturation processes and programs are in place.

\subsubsection{Organization Aspect of a Global Business}

One of the key differences between international trade / commerce and global industry is that international trade may not require as much acculturation of overseas consumers, as a global industry business would require. As such minimal acculturation is required of international firms. Multinationals, as the term suggests, operate in multiple nationalities and evolve multi-domestic strategies, and acculturation may not be imperative for business success. However in organizations that are transnational and where global movement of people across borders is significant, acculturation is imperative and must be attended to, for the successful operation of transnational and global companies. Further in transnational / global companies, owing to the rationalization of decision systems and operations, and their integration worldwide, a cohesive organization culture tends to develop; one that has far reaching impact on performance. 


\subsubsection{Resistance to Acculturation}

One of the most important concepts of acculturation processes is cultural distance, seen as a triangulation of geographical separation, affective connection and historical familiarity between the home country and host markets / countries. In acculturating consumers / customers in host markets, firms need to keep in mind that the cultural distance from the home market to host market is different from the cultural distance of the host market to the home market (Buckley, 2014). Tightly coupled with the postulate of acculturation processes, for host country / overseas consumers as well as for a global business organization, is the issue of resistance by overseas country consumers and their organizations that are nested in country and ethnic culture ethos, to such acculturation processes. As such it is important to take into cognizance host country / overseas sentiments, the context of their society, and the imperative for globalization by host country / overseas governments. It is also necessary to delicately balance such programs and processes of acculturation so as to not ignite adverse reactions but smoothly transit both consumers and participating organizations to enhanced realizations of the market offerings by the international / global businesses.

\subsubsection{Development of a Cohesive Global Organization Culture}

The counter-play of acculturation of global businesses and the resistance to acculturation by individual overseas country cultures is propelled by the need for the global business to succeed as guided by global systems and procedures. In this scenario, the development of a global mindset (as brought out in 3.4.5 above) leads to the evolution of a cohesive global organization culture that could exhibit one or more aspects of firm specificity, industry specificity, and market specificity. It has to be noted that the development of a cohesive global organization culture is also impacted by cultural distance. Further, in transnational / global companies, owing to the global rationalization of decision systems and operations, and their integration worldwide, the cohesive global organization culture tends to get reinforced, and has far reaching impact on business performance and success.

\subsection{Achieving Global Marketing Synergies}

With increasing trends towards globalization and international business, both by firms in developed countries as well as by firms of emerging markets, achieving global marketing synergies become important to gain a competitive edge. Global marketing resonance occurs when key success factors (KSF) of the global market are met by partial global strategies (given that complete global strategies are not practically achievable); some examples are those of global $\mathrm{R} \& \mathrm{D}$, global branding, global customers or global accounts. Global transactional facilitators of information, servicing, financing and logistics need to be in place and well-tuned to conduct global commerce. With the advent of the world-wide web, these capabilities have increased. Global product strategies are to be in place, appropriately adapted for each country or region, simultaneously mapped to stages of international market development. Cross border synergies on account of pricing through appropriate transfer pricing mechanisms, have to be appropriately exploited. Firms could also take the path of (i) home country manufacture and global marketing with local delivery that includes servicing, warehousing, packaging facilities and use of local logistics; or (ii) global marketing with global sourcing along with local manufacture and local delivery. The use of relational capabilities for achieving global efficiency could at times be exploited in particular contexts of geographies and product markets. Further large firms need to undergo periodic reconfiguration of management control to suit changing business environment. Also beneficial in achieving synergies could be periodic rescaling to suit to changing tastes and preferences among consumers and, consequently, changing demand conditions. Consequent redo of metrics and key performance indicators may be required.

For large global organizations, global rationalization is an imperative that needs consideration to achieve glo bal synergies. The ultimate goal of global strategy should be to achieve optimal integration and rationalization of operations and decision systems on a global scale. Potential synergies arising from coordination and integration of strategy and of decision systems across country and product markets has to be captured, and maximal efficiency in the optimal allocation of resources worldwide achieved. Focus on the unique competitive advantages provided by the multi-country character of operations is thus the key to success in the global marketplace. Global rationalization could also suggest the emergence of global consumers.

In the Indian scenario, achievement of global marketing synergies has been effectively attempted by some firms (Chattopadhyay et. al, 2012). The most common synergy providing market strategy is called 'leveraging of strong domestic market position' as has been the case with Indian cellular firms attempting to garner share in African markets. The second synergistic market strategy is the 'cost leader or frugal engineering strategy' that was adopted by Tata Motors in launching and marketing the economy car - Tata Nano, with the firm attempting 
to combine country specific strengths such as low labor cost, and firm specific competencies such as engineering expertise. The product did not capture the imagination of the consumer as an effective economy value proposition car as, probably, the consumer had higher aspirations from an economy car than what Tata Nano could provide. The third synergy providing market strategy is the 'niche customizer strategy'; a strategy driven by customer insights to obtain local needs, superior technical capabilities, and small volume manufacturing with high quality and high profit. One such example would be the Indian high quality vegetarian restaurant business Saravana Bhavan -- that has wide presence in South India and international presence in countries including USA and Singapore. The fourth market strategy attempting synergy is the 'global brand builder' that could include (i) a disruptive or breakthrough inno vation followed by a reverse innovation as was attempted with the Tata Nano (ii) acquisitions to obtain beachhead followed with active pursuit such as Tata acquisitions of Tetley tea, Jaguar and Land Rover cars; and (iii) pursue further what starts of as organic growth, as is the case with the Indian software industry firms - Wipro, Infosys, TCS and HCL.

\subsection{Overcoming Market Acceptance Barriers or Overcoming Global Negatives}

Rationales for going global are positive factors and may be called global positives. Restrictions and hurdles for going global, and obstacles to successful market acceptance of an emerging market firm's products in an overseas market are negative factors and may be called global negatives. For successful implementation of a marketing strategy overseas, it is not enough to identify the strengths or global positives and form a justification based on them; but it is also necessary that the global negatives be addressed and overcome.

The first step in overcoming global negatives is to identify the global negative/s. To aid identification of the global negatives, the exporting firm needs to identify the source of the global negative/s. A single global negative could have multiple sources. The source could be the consumer, the government, the channel, and the competition. Consumer related global negatives could be (i) need / benefit/ feature related; (ii) image related, which could include the image of the brand, image of the firm, and image of the home country; (iii) habit / attitude related; (iv) there could be a risk of purchase in factors such as quality and servicing to overseas customers of home country products; and (v) there could be other global negatives specific to a firm or product market that can be uncovered by research. Government related global negatives could be (i) policy related; (ii) attitude related; and (iii) other global negatives specific to a given bilateral relation between two countries that have to be uncovered through a careful study of home country - host country government relationship. Channel related global negatives could be (i) image related and may be of the brand, firm, home country or a combination of them; (ii) terms and conditions related; (iii) because of too many competitors vying for the same channel; and (iv) other specific channel negatives specific to a given product market. Competition related global negatives could be (i) the presence of global competitors in host country markets; (ii) presence of strong national competitors in host country markets; (iii) high intensity of rivalry between firms of the same industry; (iv) low margin and high expenses making competition even more difficult; and (v) specific competitive related negatives, specific to a given geography of a product market. Global negatives could be categorized into strong global negatives and weak global negatives.

The second step is to identify the resource requirement to address the source, and correspondingly the global negative. The firm has to check if the resource requirement is within the capacity of the organization, and how best the negative can be addressed, given the resources of the organization. If the resources are not within the capacity of the organization, then the firm has to raise these issues with the respective trade associations, or the industry support forums to bring in joint action.

The third step is to lay out the time period and the processes / procedures required to overcome or meet some of the challenges of the global negative. The firm has to consider whether it would continue to market the product and simultaneously address the negative, or if a sequential action is desirable. If sequential action is needed then it needs to put its marketing efforts on low key and step up its efforts and campaigns to address the global negative. Assistance of home country governments in disseminating information and organizing events to overcome negatives may play an important role. It needs to be examined if the global negative manifests itself differently in different countries, or it is the same across countries where the considered firm is marketing its products; in such a case a country by country campaign or a single campaign covering all markets would be appropriate respectively.

The last step would be to establish performance indicators to the process of overcoming global negatives, measure these performance indicators and manage them to achieve desired results. Some common performance indicators could be customer satisfaction, channel acceptances, government clearances, improved brand equity, 
and higher brand recall. The firm needs to check on a periodic basis, how the improvements in addressing global negatives compare with the actual resources invested, and the lessons derived for the future.

Overcoming market acceptance barriers or global negatives is ideally supposed to take a firm forward in terms of representation in overseas markets. The objective would be to move the firms from a negligible representation or from an entry position, to a significant or even a beachhead position in the market, from where it could build on its technical expertise and capabilities. This should happen provided the global logic has been worked out carefully.

We take two global negatives - problems in branding and problems in servicing -- and address some issues of overcoming market acceptance barriers.

\subsubsection{Branding}

Lack of a clear global theme could be one source of the problem in branding. The other is that whenever a branding scheme is proposed overseas, it is better to be right the first time. Emerging market brands should attempt at less teething problems at the outset. Otherwise it could lead to image and identity problems. A brand is a promise of delivery on some dimension of product, service or image. If this promise is not delivered, there could be problems in branding. Global brands are built by not only delivering the right promises but considerable expense in advertising and promotions. For emerging market firms going overseas, such expenses may be very high, and other methods to build awareness and a sense of ownership in the product needs to be examined; for example, contests on a continuous basis. More often than not, the lack of marketing expenditure results in a weak brand. Quality associations need to be upped to better project the images of products coming from newly industrializing countries; this may occur through premier dealerships, track record of service, and adhering to technical specifications consistently.

For large established firms in global markets, extant literature offers prescriptions for firms towards global brand leadership (Aaker \& Joachimsthaler, 1999). These include the sharing of insights and best practices across countries, establishment of uniform brand-planning process across markets and products, assignment of global brand managers to create cross-country synergies, and the need to execute brilliant brand-building strategies. Adaptation to local conditions is as important as the global planning process, and this aspect can be circumvented by glocalization of brand building programs.

\subsubsection{Servicing}

The first and simplest problem occurs when the ambience at the overseas service center does not exude a reassuring style. The second is more fundamental and occurs when the product itself has basic quality problems. The third occurs when the customer does not perceive value in the servicing offer. Customer dissatisfaction may be avoided for such problems with the least expenses, if timely interventions are made. Mobility in servicing provisions across the country or region markets go a long way in communicating the global nature of the brand.

\subsubsection{Addressing Competition}

It is necessary to categorize the competition into (a) global competitors, (b) national competitors, and (c) local competitors. It is also necessary to distinguish competition into (a) near competitors, and (b) distant competitors.

The firm may need to take into account both near and distant global competitors. In the case of national competitors, the firm needs to emphasize near competitors than distant competitors. In the case of local competitors, it needs to only look at near competitors.

In a niche market, a unique position may pay off. In the case of a segment market, it may be well worth to examine the alignment of the considered firm with the dominant global competitor, as there might be positive linkages in the market for that position. In any case, the competitive position maps need to be plotted and an appropriate positioning strategy needs to be chosen. This is an important exercise in addressing competition.

Competitor strengths, weaknesses and strategies need to be studied before decisions are made for the marketing mix of the home country's products. An inventory of strengths of near global and near national competitors needs to be compared with the home country firm's strengths to get a realistic estimate of the realizable market.

Dynamic reactions to competition can be addressed mainly with respect to the first main competitor and the second main competitor, as otherwise a plethora of reactions are possible that may send confusing signals to the market.

\section{Discussion}

There have been, as of recent times, initiatives adopted by governments of emerging markets such as India, to 
encourage start-ups. In such a scenario, many small emerging market start-up firms can go overseas, especially in the apparel and fashion industries, where India has inherent cost advantages due to low cost labor. It is thus interesting to examine how such start-up firms of emerging markets fare overseas especially in the developed countries of Europe and North America. Research on entrepreneurial strategies for emerging markets indicates positive relationship between firm performance and having a foreign parent; negative relationship between firm performance and number of products / services offered; and requirement of an executive social capital for better initial firm performance (Collins and Reutzel, 2016).

The ensuing discussion was derived after an interview with a leading apparel exporter based in South India, a start- up in 2006 that has two foreign parents, and specializing only in formal shirts (range is narrow). By investing overseas, the company wants to come closer to the customer and also provide better value to the customer by eliminating intermediaries in the process.

The strength of the firm is in low cost, efficient manufacturing that is leveraged through buying houses, offices of customer. Global customer logic is integrated overseas by the buyer (for example, J C Penney), who builds and maintains the product designs. This way the apparel manufacturer acts as a service center for making the apparel ready. The fabric of particular mills in India is also specified by the overseas buyer. Global purchasing logic exists clearly. The buyer buys from among a group of countries after clearly identifying the quality and servicing characteristics of various vendors in these countries through a detailed vendor rating system. The presence of global industry logic is clear as the key success factors are the same worldwide.

Addressing the global negatives, India is perceived as a source for low value, high volume items such as shirts and ladies tops, although this perception is slowly changing and small volumes of suits are being exported as well. Some advantages in cotton yarn, however, are seen. The firms here are being seen as less responsive to customer needs/benefits/features. The firms are also being seen as not providing enough value to the customer. The firms are not able to supply enough to satisfy the large requirements of apparel of the customer. There is a customer perception that Indian firms are less able to make sophisticated products such as suits. Further the customers perceive a risk in buying sophisticated products. When there is a clear economic benefit that clearly outweighs this perceptual gap, then they will source sophisticated products from India. With respect to the government, India actively encourages modernization by giving interest subsidies for fresh investments in this sector. Garmenting has been removed from the small scale sector so that larger firms can compete. This indicates that the regulatory logic for going abroad for apparel is positive. There are image problems in the channel.

Global competitive logic used to be influenced by the allocations made through the quota system. With respect to the current apparel market environment, quotas have been abolished in the post WTO period, and buyers are free to source their entire requirements of apparel from low cost suppliers. This indicates the presence of global competitive logic. As such firms in countries on quotas with high cost structure have closed, and a huge amount of consolidation of apparel making units across borders have taken place. The product category image continues to be weak for India, with China still being the leader of trade in apparel. China used to offer better value by offering better quality garments at cheaper prices, but now finds the cost going up. The market share of China is declining, with countries like Bangladesh with costs much lower increasing their market share. In the apparel market there are two categories of players - converter firms who do the bulk of the business (approx. 90\%) and only take responsibility for sampling and manufacture; and the other category are the 'full package' firms (approx. $<10 \%$ ) who take all responsibilities except retailing (this includes - design, sampling, manufacture, shipping, warehousing, and distribution). Bangladesh is the lowest cost country in the world and operates on the converter model. Sri Lanka has many foreign firms who set up shop on their land and go by the 'full package' process.

In the above environment, the problems have to be addressed at the micro or firm level, as well as the macro or industry level. Awareness building and education of buyers was cited by the interviewee as an important aspect of resource deployment at the macro level, suggesting the importance of global information logic.

\section{Conclusions}

Strategic marketing is important decision making in marketing, and many marketing decisions in the process of a firm going global are strategic in nature given their high revenue / investment / expense impact and /or because of the long term implications it carries to the marketing processes of the firm. The strategic nature of decision making for a firm going global also arises owing to uncertainty in global markets, and hence there is a need for contingency planning.

Motivators and positive factors are a must for a firm to go global. Positive factors also called global positives are exemplified by global logic. Global logic can exist in customers, purchasing, information, industry, size, 
competition, and regulation. Existence of global logic for a firm suggests it has a reason for globalization. Therefore, global logic is a must for global entry. Global entry also involves decisions such as (a) whether to go abroad, (b) which markets to enter and (c) how to enter those markets.

There are a number of factors involved in successfully implementing global marketing strategy. These include globalization vs. adaptation, the marketing organization issues, identification of phase of international market development, partial global strategies, and development of global mindset. The important aspect for an emerging market firm going overseas is to address global negatives or to overcome market acc eptance barriers. Apart from firming up on global logic, it is necessary to examine that hurdles, obstacles and negative factors (in consumer psychology, in the business environment, and in the market place), are addressed to make the emerging market firm's products and services garner a reasonable share of the overseas market and make it truly global. All firms going global have to accommodate in their strategies and processes, an affinity to acculturation to truly achieve a cohesive global culture in their organizations and the product markets. Last but not the least is the increasing imperative in the face of competition, for the firms to achieve all possible synergies in the global market place that gives them an edge in securing business for their firms.

Given that conditions for global entry and implementing global marketing strategy are met and the three success moderating factors are addressed, the study recognizes that it is necessary to address the competitive forces in the global environment to be able to obtain an optimal share of the market.

In summary, it can be stated that that (i) an explicit process to address global negatives is required to overcome the perceptual gap of emerging market firms on deliverables; and (ii) explicit attention to the achievement of global market synergies has to be given by global marketing strategists.

\section{Acknowledgments}

The author thanks Mr. Sarbajit Ghose, Director of a leading apparel exporting firm, Laguna Clothing Pvt. Ltd., located in Bangalore, India, for his inputs on the discussion.

\section{References}

Aaker, D. A., \& Damien, M. (2010). Strategic market management: Globalperspectives, Wiley.

Aaker, D. A., \& Erich, J. (1999). The lure of global branding. Harvard Business Review, Nov-Dec.

Buckley, P. J. (2014). Adam Smith's theory of knowledge and international business theory and practice. Journal of International Business Studies, 45, 102-109. https://doi.org/10.1057/jibs.2013.44

Chattopadhyay, A., Rajeev, B., \& Aysegul, O. (2012). The new emerging market multinationals. Tata McGraw-Hill Education Private Limited.

Collins, J. D., \& Christopher, R. R. (2016). Entrepreneurial strategies for emerging markets. Journal of Business Strategies, 32(2), 47-66.

Cuervo-Cazurra, A., \& Ravi, R. (2014). Understanding multinationals from emerging markets. Cambridge University Press. https://doi.org/10.1017/cbo9781107587632

Cuervo-Cazurra, A., William, N., \& Seung, H. P. (2016). Emerging market multinationals. Cambridge University Press. https://doi.org/10.1017/cbo9781139681049

Douglas, S. P., \& Samuel, C. C. (1995). Global marketing strategy. McGraw Hill International.

Jeannet, J. P. (1999). Managing with a globalmindset. Prentice Hall.

Kotler, P., \& Kevin, L. K. (2016). Marketing management. Pearson education, Fifteenth edition.

Meyer, K. E., \& Mike, W. P. (2016). Theoretical foundations of emerging economy business research. Journal of International Business Studies, 47, 3-22. https://doi.org/10.1057/jibs.2015.34

\section{Copyrights}

Copyright for this article is retained by the author(s), with first publication rights granted to the journal.

This is an open-access article distributed under the terms and conditions of the Creative Commons Attribution license (http://creativecommons.org/licenses/by/4.0/). 